\title{
Contribuições da infografia para o treinamento de profissionais que atuam com alunos usuários de Sistema FM
}

\author{
Contributions of the infography to the training of professionals that deal with \\ students users of FM system \\ Camila Medina, Tacianne Kriscia Machado, Regina Tangerino de Souza Jacob, Cassia \\ Leticia Carrara Domiciano
}

Design da informação, infografia, tecnologia assistiva, sistema de frequência modulada

\begin{abstract}
O Sistema FM é uma ferramenta educacional que auxilia crianças com deficiência auditiva usuárias de próteses auditivas e/ou implantes cocleares na melhora da compreensão do sinal de fala e diminui o ruído de fundo, principalmente no ambiente escolar. Recentemente, o SUS passou a disponibilizar esta tecnologia, tornando-a mais acessível à população brasileira. Para sua adequada implantação é necessário um trabalho intersetorial caracterizado pela articulação entre os Sistemas Educacional e de Saúde para a transmissão de informações para profissionais que atuam com a adaptação do Sistema FM em todo o país. Para colaborar com essa necessidade, foi desenvolvido um Portal de orientação, cujo conteúdo foi apresentado basicamente através de Infografia. Este artigo apresenta o processo de criação deste ambiente virtual, bem como a sua avaliação por 30 profissionais através da Ficha de Pesquisa Motivacional, que avalia a motivação do usuário em quatro domínios: "Estimulante", "Significativo", "Organizado" e "Fácil de Usar". Resultados demonstraram alta satisfação motivacional, onde os particiantes consideraram o portal como impressionante. As respostas do questionário também foram analisadas de acordo com os quarto princípios do Design de Informação: comunicação, cognição, estética e usabilidade. O domínio "Organizado" e o princípio da "Estética" foram os mais pontuados, o que demonstra a facilidade de leitura de conteúdos complexos e extensos através dos infográficos. O acesso aos módulos impactou positivamente no trabalho dos profissionais.
\end{abstract}

information design, infographic, assistive technology, frequency modulation system

FM System is an educational tool that assists children with hearing impairment in general of hearing aids and / or cochlear implants in improving speech signal comprehension and reducing background noise, especially in the school environment. Recently, SUS has made this technology available, making it more accessible to the Brazilian population. In order to adapt it, an intersectoral work is required for the transmission of information to communication systems and systems for the transmission of information to professionals who work with an adaptation of the FM System throughout the country. To support this need, a Guidance Portal was developed, the content of which was presented basically through Infographics. This article presents the process of creating the virtual environment, as well as its evaluation by 30 professionals through the Motivational Research Sheet, which evaluates a user's motivation in four domains: "Stimulating", "Significant", "Organized" and "Easy Use ". Results showed high motivational satisfaction, where the participants considered the portal as impressive. As answers of the questionnaire were also analyzed according to the production room of Information Design: communication, cognition, aesthetics and usability. The "Organized" domain and the principle of "Aesthetics" are so much more punctuated, that they demonstrate a facility of reading complex and extensive contents through the infographics. The access to the modules had a positive impact on the work of the professionals.

Anais do 8 CIDI e 8 CONGIC

Guilherme Santa Rosa; Cristina Portugal (orgs.)

Sociedade Brasileira de Design da Informação - SBDI

Natal | Brasil | 2017

ISBN 978-85-212-1305-5
Proceedings of the $8^{\text {th }}$ CIDI and $8^{\text {th }}$ CONGIC

Guilherme Santa Rosa; Cristina Portugal (orgs.)

Sociedade Brasileira de Design da Informação - SBDI

Natal| Brazil | 2017

ISBN 978-85-212-1305-5 


\section{Introdução}

O Sistema de Frequência Modulada (FM) é uma ferramenta educacional desenvolvida para crianças com deficiência auditiva, usuárias de próteses auditivas e/ou implantes cocleares, que tem como objetivo melhorar a compreensão do sinal de fala em ambientes ruidosos, reverberantes e na distância entre o indivíduo e a fonte sonora, principalmente em ambiente escolar (Blasca, Ferrari \& Jacob, 2006; Jacob \& Queiroz-Zattoni, 2011; Jacob et al, 2012) Tratase de um recurso de tecnologia assistiva composto por duas partes: transmissor (em sala de aula, usado pelo professor) e receptor (dispositivo instalado junto à prótese auditiva). Seu objetivo é melhorar a comunicação entre os deficientes auditivos, professores, colegas e familiares (BRASIL, 2015).

Há anos, a inclusão do Sistema FM em salas de aula regulares beneficia crianças com deficiência auditiva. Porém, sua utilização tornou-se mais acessível através da incorporação do Sistema de FM ao Sistema Único de Saúde (SUS), que ocorreu a partir da publicação da Portaria 1.274, de 25 de junho de 2013, a qual inclui o Sistema FM na Tabela de Procedimentos, Medicamentos, Órteses, Próteses e Materiais Especiais (OPM) (Brasil, 2013). Desde sua implantação até abril de 2017, o SUS disponibilizou cerca de 4.500 dispositivos para a população' 1 .

Para a adequada implantação de um Programa de Concessão, Adaptação e Acompanhamento do Sistema FM em estudantes com deficiência auditiva nas escolas brasileiras é necessário um trabalho intersetorial, caracterizado por uma cuidadosa articulação entre os Sistemas Educacional e de Saúde. As ações em rede devem integrar os diferentes níveis de atenção da pessoa com deficiência auditiva, conforme a política interministerial Viver Sem Limites (SDH-PR/SNPD, 2013).

A capacitação do profissional atuante em Serviços de Saúde Auditiva, quanto ao uso do equipamento é de fundamental importância, bem como o seu constante aprimoramento. Só assim todas as recomendações propostas pelos Ministérios da Saúde e Educação poderão ser gradativamente implantadas e o aluno com deficiência auditiva poderá ter o benefício efetivo com esse tipo de tecnologia assistiva.

No Brasil, em virtude da grande extensão territorial e, principalmente devido às diferenças existentes na formação profissional, a necessidade da criação de programas educativos na área da saúde torna-se cada vez mais necessária (Ferrari et al., 2010). Nesta direção o design pode, em diferentes aspectos, contribuir para uma ação educativa mais efetiva em saúde, através do desenvolvimento, em equipes multidisciplinares, de materiais instrucionais e informativos diversos.

Lopes, Coutinho \& Barbosa (2012) concluíram em seu estudo sobre a contribuição de metodologias de design para a Prática Pedagógica que existe necessidade de ampliar e fortalecer as pesquisas que articulam processos interventivos de design de base educacional e formadora, junto aos não especialistas na área.

É a área do Design da Informação (DI) que abriga essas ações em design, pautadas pela efetiva comunicação de conteúdos variados a usuários também diversos. Por isso o DI é focado neste artigo, que apresenta o desenvolvimento de um website, o Portal Sistema FM, disponibilizado no endereço eletrônico www.portalsistemafm.fob.usp.br. Pelo uso da Teleducação Interativa e a internet é possível oferecer atualização sobre a tecnologia assistiva aqui destacada, alcançando profissionais distribuídos por todo o país.

Após desenvolvimento, o material foi avaliado por profissionais da área, utilizando-se uma Ficha de Pesquisa Motivacional (FPM), a fim de verificar a eficácia deste ambiente virtual de transmissão de informações sobre Sistema FM utilizando a Teleducação Interativa.

\section{Design da Informação e Infografia nas ações educativas}

O design da informação é uma atividade projetiva que busca o entendimento conceitual entre elementos e seus significados e relações, transpondo a estruturação e aglutinação da

\footnotetext{
${ }^{1}$ Disponível em: http://tabnet.datasus.gov.br/cgi/tabcgi.exe?sia/cnv/qgSP.def
} 
informação através das relações entre conteúdo, comunicação visual e linguagem. Atua como agente facilitador na seleção, estruturação e organização das informações em sistemas complexos (Passos \& Moura, 2007). Junto ao Web Design, possui a capacidade de "potencializar o aprimoramento e concepção de artefatos informacionais" (Duarte, 2016).

Pena de Sá $(2016)^{2}$ organizou, através de levantamento bibliográfico, os princípios do Design da Informação em quatro grupos.

1. Comunicação: organizar, categorizar, hierarquizar, personalizar e diferenciar elementos informativos. Alguns de seus princípios são o LATCH (Local, Alfabeto, Tempo, Categoria, Hierarquia); a Modulariedade (agrupamentos funcionais por semelhança) e o Esforço Mínimo (indivíduos preferem ferramentas familiares e fáceis de usar).

2. Cognição: fundamentar decisões estéticas no processo de criação do projeto gráfico. Seus fundamentos são os estilos de aprendizagem (método sensorial de preferência do indivíduo); os princípios da percepção da Gestalt; memória (direcioná-la para facilitar que a informação seja lembrada); wayfinding (auto-orientação dentro de um ambiente) e sobrecarga Informacional (excesso de oferta de informações).

3. Estética: proporcionar a facilidade de percepção. Seus princípios são a estrutura, a legibilidade, a proporção e a harmonia.

4. Usabilidade: promover melhor experiência de uso dos sitemas interativos. A visibilidade (as funções devem ser claramente visíveis); o feedback (retorno de informações mediante uma ação); as restrições (reduzem a quantidade e variedade de ações); a consistência (quando as partes similares são expressas de modo semelhante); e o affordance (como o usuário interage com o objeto ou ambiente) são seus princípios.

Já os infográficos são usados como ferramentas do Design da Informação, por vezes utilizados na área do Ensino, em mídias impressas ou digitais. São representações visuais de caráter informacional, com alto poder de atração, que aliam texto e imagem (fotografia e/ou ilustração) para revelar o desconhecido e explicar o complexo, de maneira simples, sintética e com foco no receptor da mensagem (Fassina, Cavalcante \& Andrade, 2009, p. 290).

A infografia opera como complemento de ensino no contexto de interatividade e dinamicidade, modernizando o texto científico de forma a torna-lo mais didático e adequado ao contexto educacional a que se aplica (Pessoa \& Maia, 2012).

Segundo Cairo (2008, p. 16), a infografia permite que os dados, transformados em informação visual, tornem-se atraentes por si só, sem necessidade de artifícios, seja em uma página impressa ou na web. A infografia deve funcionar como uma ferramenta de análise da realidade a serviço do leitor. Sua prioridade não é gerar páginas mais leves, dinâmicas ou com um design impactante - ainda que o faça muitas vezes - mas melhorar a compreensão em primeiro lugar. Ainda segundo o autor, a incorporação de ferramentas interativas na publicação digital impulsiona uma troca de paradigma na visualização de informação: a liberdade tradicional que o leitor possui em ler os conteúdos de uma infografia na ordem que achar melhor, criando sentido a partir dos dados e o formato digital, com a construção de interação feita, não mais a partir da infografia propriamente dita, mas pelo design de navegação.

\section{O Ambiente Virtual de Aprendizagem}

O desenvolvimento do conteúdo do Portal Sistema FM foi baseado nas fases de desenvolvimento de design instrucional propostas por Filatro \& Piconez (2004), conforme etapas abaixo.

\subsection{Primeira etapa: análise e planejamento}

A primeira etapa envolveu a identificação de necessidades de aprendizagem, definição de objetivos instrucionais e o levantamento das restrições envolvidas. Essa etapa baseou-se no protocolo da Academia Americana de Audiologia "Remote Microphone Hearing Assistance

2 adaptado de Petterson (2012), O'Grady e O'Grady (2008), Lidwell et al. (2010), Rogers et al. (2013) e Garcia (2012).: 
Technologies for Children and Youth from Birth to 21 Years" (American Academy of Audiology, 2011).

\subsection{Segunda etapa: desenvolvimento do conteúdo e design}

Nessa etapa, foi realizada a elaboração do conteúdo. O conteúdo textual foi transformado em infográficos de acordo com os princípios do Design da Informação para que o ambiente virtual de aprendizagem atendesse aos anseios e necessidades dos usuários.

Foram selecionados os principais temas que deveriam ser abordados no Portal Sistema FM para a transmissão de informações sobre o Sistema FM aos fonoaudiólogos, sendo então desenvolvido o layout. O site é composto por sete módulos:

1. Módulo 1: RUÍDO E ESCOLA

2. Módulo 2: SISTEMA FM

3. Módulo 3: ADAPTAÇÃO E ACOMPANHAMENTO DO SISTEMA FM

4. Módulo 4: ORIENTAÇÕES AOS PAIS E PROFESSORES

5. Módulo 5: DEPOIMENTOS

6. Módulo 6: SOLUÇÕES DE PROBLEMAS

7. Módulo 7: AVALIE O PORTAL

Vale ressaltar que, além dos módulos sobre o Sistema FM, alguns materiais instrucionais também foram desenvolvidos e outros foram disponibilizados pelas empresas fabricantes dos dispositivos, como tutoriais em video; vídeos com depoimentos de usuários de Sistema FM; tutoriais para impressão, contendo tanto procedimentos profissionais, quanto problemas e soluções do Sistema FM; questionários/inventários para impressão.

Uma identidade visual foi elaborada para o portal e para diversos materiais gráficos citados, reduzindo e transformando o conteúdo textual. A linguagem gráfica adotada nesta concepção foi de ilustrações simples e diversas cores que fazem referência ao ambiente infantil e escolar, conforme mostrado nas figuras 1,2 e 3.

Todos os materiais e textos selecionados e abordados no Portal Sistema FM foram transformados em infográficos com o auxílio do design da informação. 


\section{CIDI $2017 \quad 8_{8^{\text {th }} \text { Inform }}^{\text {th } \mathrm{ClDl}}$ \\ $8^{\text {th }}$ CONGIC \\ $8^{\text {th }}$ Information Design \\ Blucher Design Proceedings

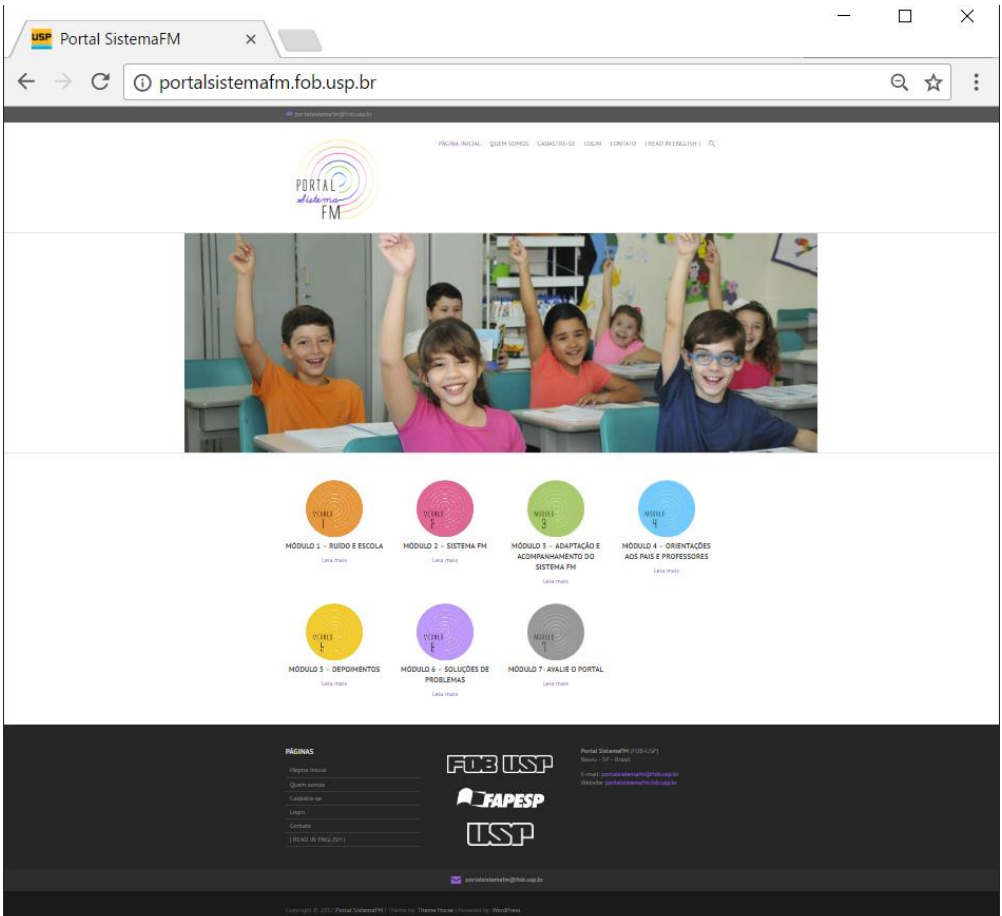

Figura 2, 3, 4 e 5: Exemplos de infográficos usados.

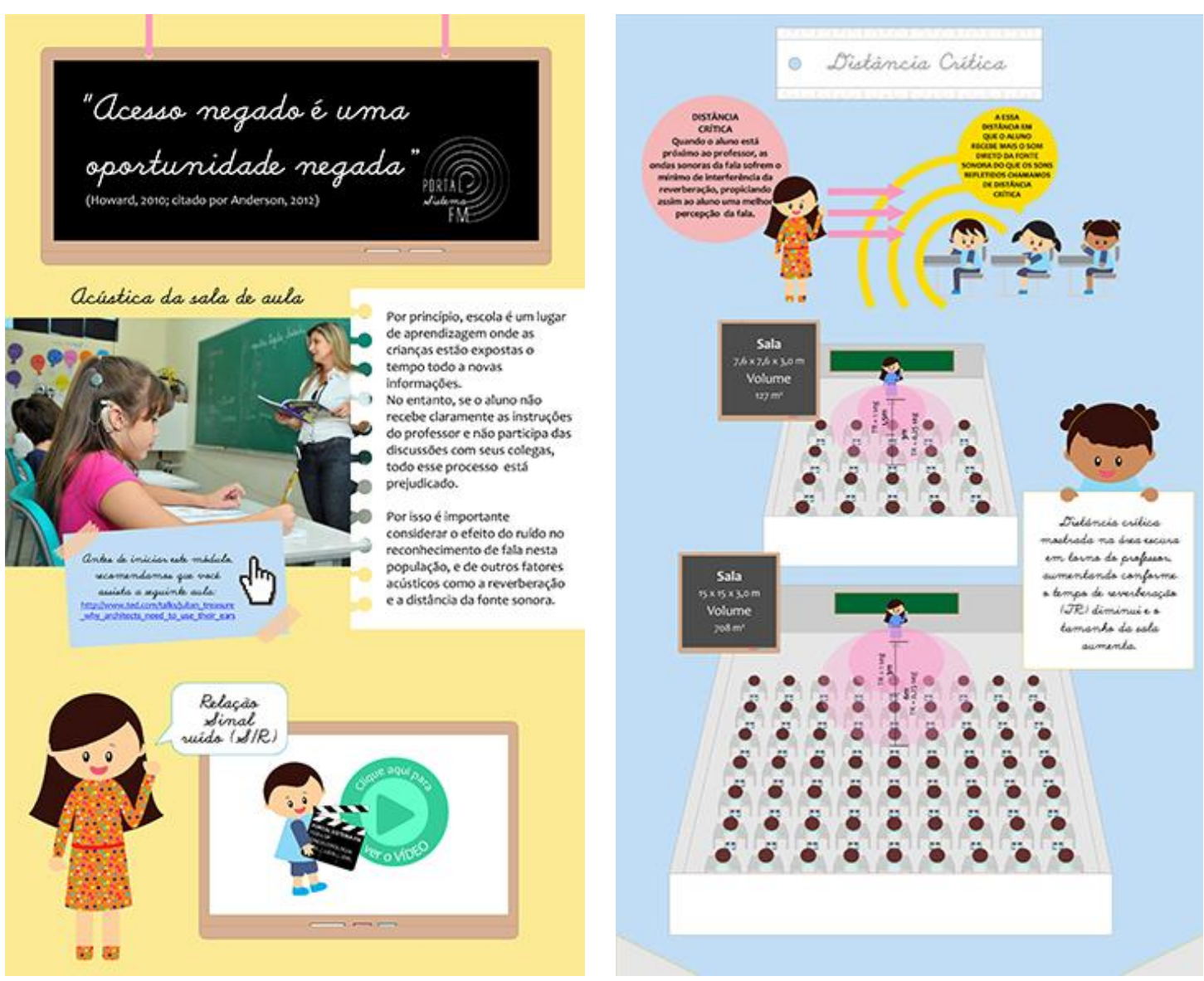




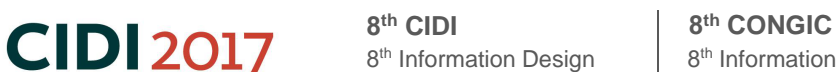 \\ NATAL
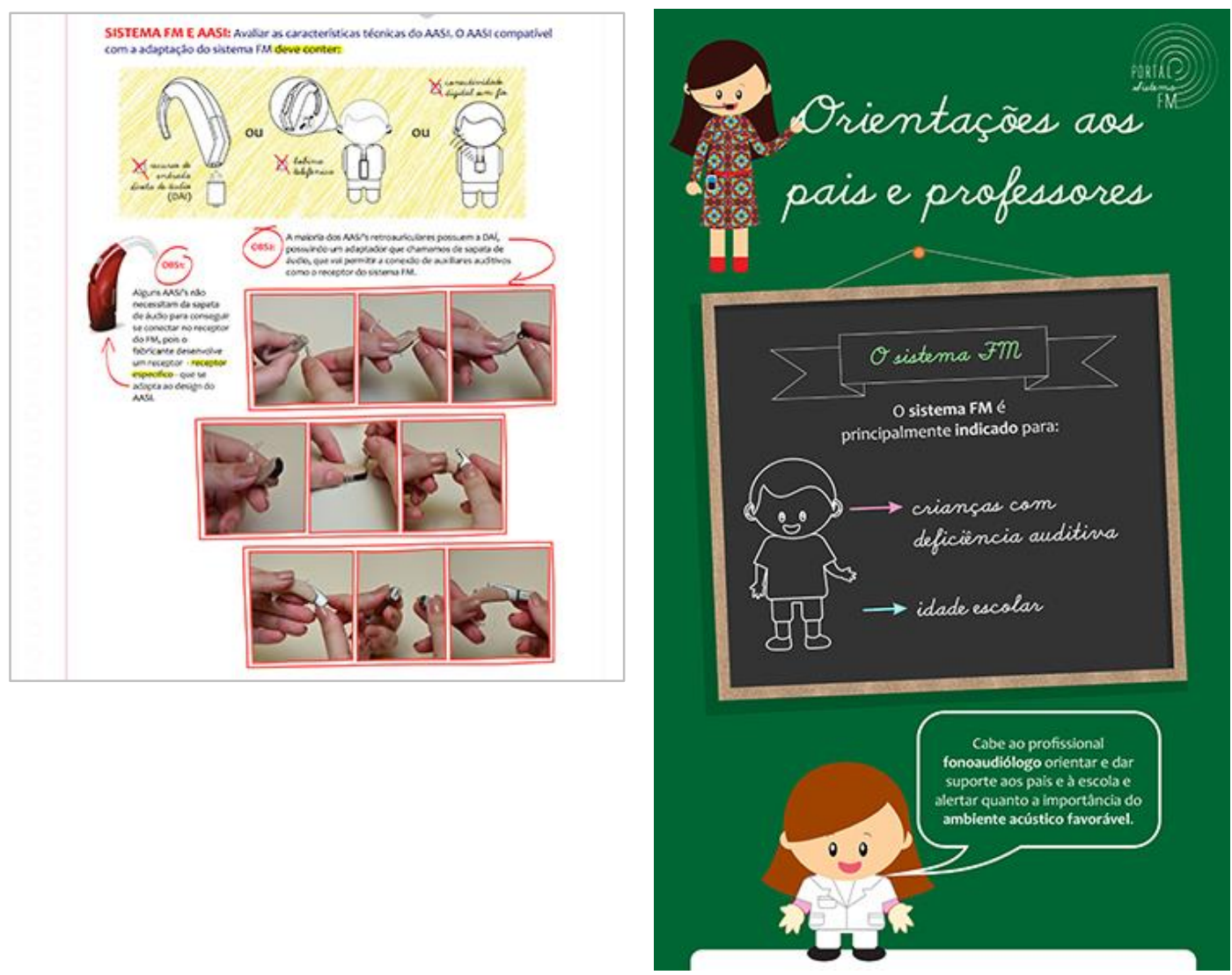

\subsection{Terceira etapa: implementação}

Foram analisados quais recursos tecnológicos deveriam ser usados para que o objetivo proposto fosse alcançado. Nessa etapa foi realizada a adequação do ambiente virtual de aprendizagem, visando a efetiva transmissão do conteúdo elaborado nas etapas anteriores.

No produto implementado, todos os módulos são passíveis de visualização em suporte digital ou ainda impressão, pois podem ser "baixados" em arquivo PDF pelo usuário do material. Envolveu ainda o acompanhamento, a revisão e a manutenção do sistema proposto.

\section{Avaliação do material}

Avaliar a eficiência do material junto ao público alvo foi outro ponto forte a pesquisa aqui apresentada.

\subsection{Procedimentos metodológicos}

A metodologia para tal se apresenta a seguir, bem como as avaliações realizadas

\subsubsection{Participantes}

Participaram voluntariamente do estudo, após a assinatura do termo de consentimento livre e esclarecido aprovado pelo Comitê de Ética em Pesquisa em Seres Humanos da instituição, 31 fonoaudiólogos:

- Idade: entre 23 a 62 anos (média 29,8 \pm 9,08 anos), um participante não respondeu;

- Tempo de experiência: três meses a 39 anos de experiência na área audiologia (média 4,29 $\pm 7,29$ anos); dois não responderam.

- Local de atuação: regiões Sudeste (94\%) e Sul (6\%) 
- Titulação: graduação (49\%), especialização (19\%), mestrado (19\%), mestrado e especialização (3\%) e doutorado (10\%)

\subsubsection{Instrumentos}

Para a avaliação da eficácia do projeto gráfico do programa de capacitação foi utilizado o instrumento Ficha de Pesquisa Motivacional (FPM) (Paixão, 2008; Blasca, 2012).

Ao finalizar o acesso aos módulos, a ficha foi utilizada para avaliar subjetivamente os aspectos motivacionais do Programa de capacitação, conforme mostra a Figura 6. 
Figura 6 - Ficha de Pesquisa Motivacional - FPM

\begin{tabular}{|c|c|c|c|c|}
\hline QUESTÕES & $\begin{array}{c}\text { Concordo } \\
\text { completamente }\end{array}$ & $\begin{array}{l}\text { Concordo } \\
\text { parcialmente }\end{array}$ & $\begin{array}{l}\text { Discordo } \\
\text { parcialmente }\end{array}$ & $\begin{array}{l}\text { Discordo } \\
\text { completamente }\end{array}$ \\
\hline \multicolumn{5}{|l|}{1 - A exibição (layout) do curso foi atraente. } \\
\hline \multicolumn{5}{|l|}{$\begin{array}{l}2 \text { - Existiu menu ou mapa no site descrevendo o } \\
\text { conteúdo que foi abordado no curso. }\end{array}$} \\
\hline \multicolumn{5}{|l|}{$\begin{array}{l}3 \text { - A informação audiovisual disponibilizada no curso } \\
\text { ajudou a esclarecer ou descrever o conteúdo. }\end{array}$} \\
\hline \multicolumn{5}{|l|}{$\begin{array}{l}4 \text { - A navegação no curso não exigiu habilidades } \\
\text { especiais, maiores habilidades ou experiência. }\end{array}$} \\
\hline \multicolumn{5}{|l|}{$\begin{array}{l}5 \text { - Existiu um título chamativo e/ou visual na página } \\
\text { inicial do curso que atraiu a atenção dos participantes. }\end{array}$} \\
\hline \multicolumn{5}{|l|}{$\begin{array}{l}6 \text { - O curso possui links, ou referências práticas, } \\
\text { incluindo páginas da web. }\end{array}$} \\
\hline \multicolumn{5}{|l|}{7 - A proposta do curso foi clara. } \\
\hline \multicolumn{5}{|l|}{$\begin{array}{l}8 \text { - O curso contou com uma função que permitiu } \\
\text { receber ajuda. }\end{array}$} \\
\hline \multicolumn{5}{|l|}{9 - O curso foi interessante para os participantes. } \\
\hline \multicolumn{5}{|l|}{$\begin{array}{l}10-A \text { informação do curso veio de fontes } \\
\text { reconhecidas. }\end{array}$} \\
\hline \multicolumn{5}{|l|}{11 - As orientações no curso foram simples e claras. } \\
\hline \multicolumn{5}{|l|}{$\begin{array}{l}12 \text { - Foi possível se mover, todas às vezes, dentro do } \\
\text { curso para o local que desejado, incluindo os acessos } \\
\text { aos recursos }\left(^{*}\right) \text { do curso. }\end{array}$} \\
\hline \multicolumn{5}{|l|}{13 - A informação contida no curso foi interessante. } \\
\hline \multicolumn{5}{|l|}{14 - A informação contida no curso estava atualizada. } \\
\hline \multicolumn{5}{|l|}{$\begin{array}{l}15 \text { - Existiu informação prática em cada um dos } \\
\text { recursos do curso. }\end{array}$} \\
\hline \multicolumn{5}{|l|}{$\begin{array}{l}16 \text { - Os recursos utilizados no curso foram consistentes } \\
\text { e facilmente visualizáveis. }\end{array}$} \\
\hline \multicolumn{5}{|l|}{$\begin{array}{l}17 \text { - A variedade de formatos usados nos recursos } \\
\text { ajudou a manter a atenção. }\end{array}$} \\
\hline \multicolumn{5}{|l|}{$\begin{array}{l}18 \text { - A informação disponibilizada no curso foi correta e } \\
\text { não tendenciosa. }\end{array}$} \\
\hline \multicolumn{5}{|l|}{$\begin{array}{l}19 \text { - Toda a informação usada no curso foi apresentada } \\
\text { usando um formato e com uma linguagem clara e } \\
\text { consistente. }\end{array}$} \\
\hline \multicolumn{5}{|l|}{$\begin{array}{l}20 \text { - Todos os recursos do curso estavam ativos e } \\
\text { funcionaram. }\end{array}$} \\
\hline \multicolumn{5}{|l|}{$\begin{array}{l}21 \text { - O curso possui características novas e inéditas } \\
\text { tornando - o mais interessante para os alunos. }\end{array}$} \\
\hline \multicolumn{5}{|l|}{$\begin{array}{l}22 \text { - Existiu pouca informação redundante ou sem } \\
\text { importância no curso. }\end{array}$} \\
\hline \multicolumn{5}{|l|}{$\begin{array}{l}23 \text { - O conteúdo do curso foi escrito sem erros } \\
\text { gramaticais ou outros erros. }\end{array}$} \\
\hline \multicolumn{5}{|l|}{$\begin{array}{l}24 \text { - Foi possível controlar no curso, a todo instante, o } \\
\text { acesso a informação desejada. }\end{array}$} \\
\hline \multicolumn{5}{|l|}{25 - Não houve surpresas no curso. } \\
\hline \multicolumn{5}{|l|}{$\begin{array}{l}26 \text { - O curso ofereceu oportunidade para a interação } \\
\text { engajando os participantes. }\end{array}$} \\
\hline \multicolumn{5}{|l|}{$\begin{array}{l}27 \text { - O curso forneceu uma quantidade apropriada de } \\
\text { informação nos seus recursos. }\end{array}$} \\
\hline \multicolumn{5}{|l|}{$\begin{array}{l}28 \text { - Todos os recursos e mecanismos de navegação } \\
\text { no site funcionaram da maneira que deveriam } \\
\text { funcionar. }\end{array}$} \\
\hline \multicolumn{5}{|l|}{$\begin{array}{l}29 \text { - O padrão de cores e os demais padrões usados na } \\
\text { página do curso foram adequados. }\end{array}$} \\
\hline \multicolumn{5}{|l|}{$\begin{array}{l}30 \text { - O curso ofereceu oportunidades de se comunicar } \\
\text { com coordenadores, organizadores e equipe técnica. }\end{array}$} \\
\hline $\begin{array}{l}31 \text { - Não importou o lugar do curso onde o participante } \\
\text { estivesse ainda assim foi possível acessar os recursos, } \\
\text { a página inicia ou sair do curso. }\end{array}$ & & & & \\
\hline $\begin{array}{l}32 \text { - Houve tempo necessário para aprender a usar os } \\
\text { recursos do curso. }\end{array}$ & & & & \\
\hline
\end{tabular}

Nota: Os recursos $\left(^{*}\right)$ foram as ferramentas interativas usadas no curso: lista de discussão, chat, etc.

A FPM é composta por 32 enunciados. Numericamente, cada enunciado é pontuado da seguinte maneira: (3) concordo completamente, (2) concordo parcialmente, (1) discordo parcialmente e (0) discordo completamente.

Os enunciados da FPM são agrupados em quatro domínios: "Estimulante", "Significativo", "Organizado" e "Fácil de Usar". O domínio "Estimulante" é agrupado pelos enunciados 1, 5, 9, $13,17,21,25$ e 29. O domínio "Significativo" pelos enunciados $2,6,10,14,18,22,26$ e 30.0 
domínio "Organizado" pelos enunciados 3, 7, 11, 15, 19, 23, 27 e 31 . O domínio "Fácil de Usar" pelos enunciados $4,8,12,16,20,24,28$, e 32 .

Depois de realizada a pontuação de cada domínio individualmente, eles são agrupados conforme a fórmula: $V=E+S ; X S=O+F$. A pontuação $V$ é a soma dos domínios "Estimulante" e "Significativo" e reflete a dimensão Valor, ou seja, o quanto é valioso este programa de capacitação. A pontuação XS é a soma dos domínios "Organizado" e "Fácil de Usar" e reflete a dimensão Expectativa para o Sucesso. Para finalizar a pontuação, os autores do WebMAC recomendaram a utilização de uma projeção cartesiana. A abscissa (eixo X) é a pontuação correspondente à dimensão Valor e a ordenada (eixo Y) é a pontuação correspondente à dimensão Expectativa para o Sucesso. Se os pontos, ou uma grande quantidade dos pontos individuais se localizarem dentro da área (Curso Impressionante!), significa que o programa de capacitação é um "Curso Impressionante", avaliando-o positivamente (Blasca, 2012).

Num segundo momento, propõe-se outra leitura do instrumento, onde alguns ítens referentes aos princípios do Design da Informação - comunicação, cognição, estética e usabilidade (Pena de Sá, 2016) - são identificados. Para tal, as questões foram separadas de acordo com estes itens, sendo que alguns se enquadram em mais do que uma categoria. Entretanto, outras questões não foram analisadas por serem específicas do contexto da audiologia ou de outros recursos do portal, alheios ao escopo deste artigo.

\subsubsection{Análise dos Dados}

Os dados coletados pelos questionários foram transferidos para uma planilha do Microsoft Excel, onde foram analisados por meio de estatística descritiva e tabelas de frequência.

As questões que se conectam aos princípios do Design da Informação também foram analisadas quanti e qualitativamente.

\subsection{Avaliação dos Questionários}

\subsubsection{Ficha de Pesquisa Motivacional - FPM (Q2)}

Esse instrumento tem o objetivo de avaliar subjetivamente os aspectos motivacionais de um Programa de Capacitação nos domínios: "estimulante", "significativo", "organizado" e "fácil de usar".

A Tabela 1 apresenta a análise estatística descritiva por domínio avaliado pelos participantes na FPM.

Tabela 1 - Análise estatística descritiva por domínio avaliado pelos participantes na FPM

\begin{tabular}{l|c|c|c|c} 
Domínio & Média & Mínimo & Máximo & Dp \\
\hline Estimulante & 22,32 & 17 & 24 & 1,536 \\
\hline Significativo & 21,97 & 16 & 24 & 2,213 \\
\hline Organizado & 22,52 & 17 & 24 & 1,568 \\
\hline Fácil de Usar & 21,45 & 17 & 24 & 1,786 \\
\hline Dp= desvio padrão & & & &
\end{tabular}

$\mathrm{Dp}=$ desvio padrão.

De acordo com a recomendação dos autores do WebMAC Professional (Small \& Arnone, 1999) e outros estudos que utilizaram a FPM (Blasca, 2012; Picolini \& Maximino, 2014) os resultados são apresentados pela projeção cartesiana (Figura 4), demonstrando a expectativa para o sucesso do programa elaborado. 
Figura 4 - Classificação do Programa de Capacitação do Portal Sistema FM

\section{Alta Expectativa pelo Sucesso}

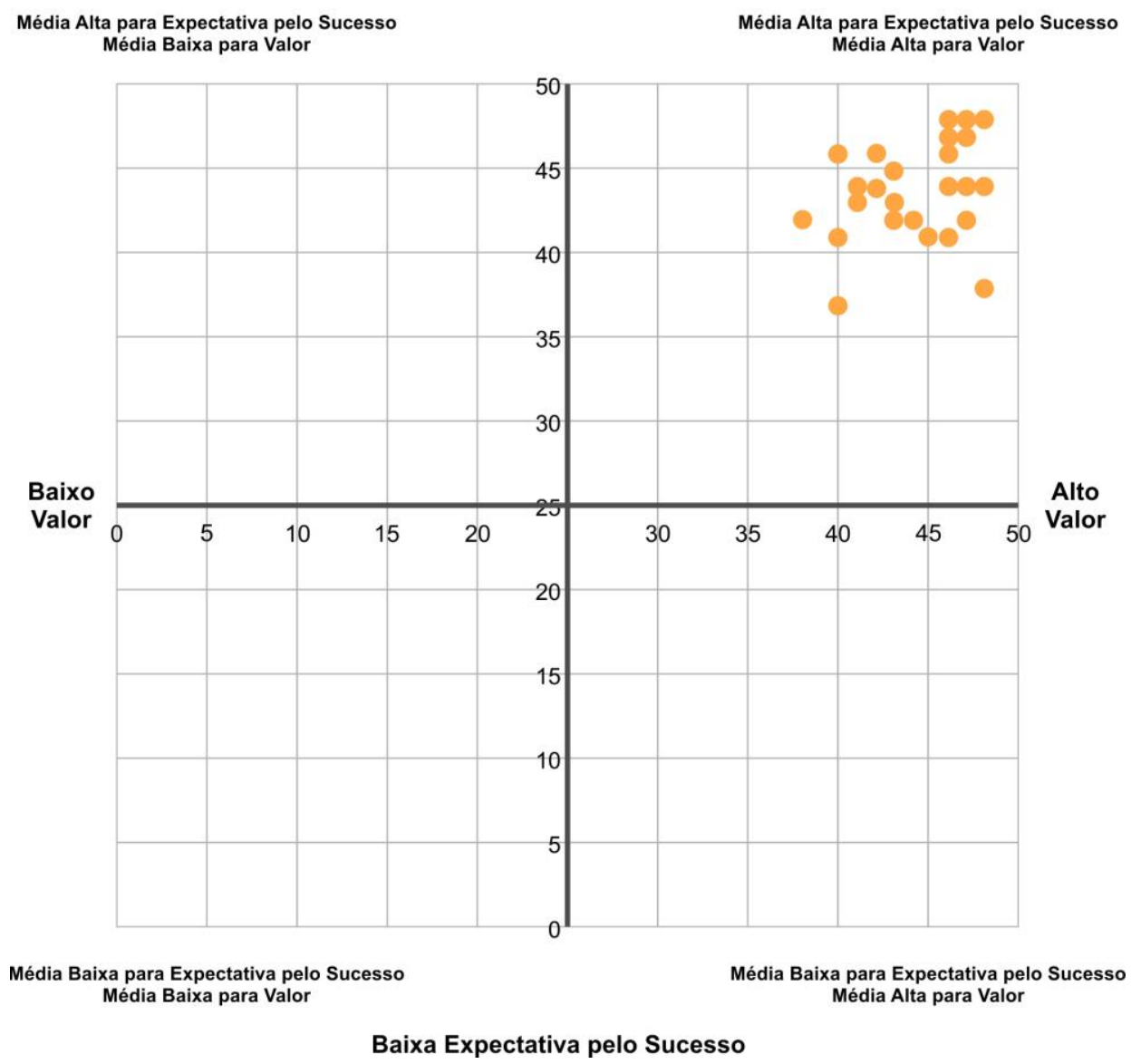

4.2.2 Avaliação por meio dos princípios do Design da Informação

Foram selecionadas 17 questões para esta separadas, neste momento, de acordo com análise baseadas nos princípios do DI.

1. Comunicação (Questões: 2, 5, 6, 9, 11, 19, 21), media 2,82

Foram avaliadas questões referentes aos componentes de navegação, que são utilizados para comunicar-se com outras partes do portal, como menu, título da página inicial, links ou referências práticas, Além disso, pontua se o curso ofereceu informações de forma simples, clara e interessante.

2. Cognição: (Questões: 1, 2, 3, 4, 5, 9, 12, 19, 20, 21, 24, 28, 29), media 2,76

Emergiram deste item questões sobre a percepção da informação audiovisual, mecanismos cognitivos de navegação (wayfinding), e forma de apresentação da informação.

3. Estética: (Questões 1,3, 5, 11, 29), media 2,88

Aspectos relacionados ao layout, informação audiovisual, padrão de cores que proporcionam maior facilidade de percepção foram avaliados.

4. Usabilidade: (Questões 2, 3, 4, 6, 12, 20, 21, 24, 25, 28), media 2,67

Este item conta com a análise de itens que referentes à facilidade de navegação $e$ interação no portal. 


\section{Discussões e Considerações finais}

O desenvolvimento de um website para o treinamento de profissionais que atuam em Serviços de Saúde Auditiva brasileiros, na rotina de adaptação e acompanhamento do usuário de Sistema FM, foi uma estratégia adotada para disseminar o conhecimento acerca do processo de adaptação deste auxiliar de audição, visto que o SUS passou a conceder esta tecnologia assistiva em 2013, sem a indicação de um protocolo a ser seguido.

O desenvolvimento do conteúdo para o Portal Sistema FM foi baseado na metodologia de design instrucional proposta por Filatro \& Piconez (2004) e da infografia, que colabora na transmissão de conteúdos extensos e complexos de uma maneira mais clara e didática . (Fassina, Cavalcante \& Andrade, 2009; Pessoa \& Maia, 2012). Em um estudo preliminar com profissionais da área da saúde, a maioria dos participantes prefere o formato infográfico a resumos textuais convencionais para relatar resultados de estudos clínicos em uma variedade de configurações (Turck et al, 2014).

O objetivo deste estudo foi avaliar a eficiência do uso da infografia para a transmissão de informação na área da saúde e faz parte de um amplo levantamento de dados acerca do tema "Sistema FM", que gerou o portal. Por este motivo, as análises demonstradas aqui, por vezes, ultrapassam esta barreira, avaliando itens referentes ao conteúdo teórico e a usabilidade do sistema. Assim, a ênfase foi dada a face dos resultados que fazem referência aos aspectos do Design, especialmente voltados à infografia, o que esclarece o uso dos princípios do Design da Informação para a interpretação dos resultados juntamente com o Ficha de Pesquisa Motivacional.

A avaliação deste website gerou resultados que demonstram alta satisfação motivacional com o Portal Sistema FM, apresentados pela projeção cartesiana (Figura 4), onde os participantes o consideraram impressionante, como no estudo de Blasca et al. (2014), o que aponta como eficaz o uso da infografia para treinamento do uso do Sistema FM para profissionais.

Os resultados também indicam que o domínio "Organizado", de acordo com os aspectos motivacionais, e o princípio da "Estética", referente aos princípios do Design da Informação, foram os mais pontuados pelos participantes, corroborando com estudos que mostram a facilidade de leitura que o infográfico pode proporcionar (Fassina, Cavalcante \& Andrade, 2009; Pessoa \& Maia, 2012; Turck et al, 2014).

Faz-se aqui um apontamento para a necessidade de utilização de recursos gráficos baseados no Design da Informação em produtos de treinamento para a área da saúde para a motivação do profissional.

Por fim, sugere-se que o Portal Sistema FM esteja em constante atualização e sejam acrescentados módulos voltados para a capacitação dos professores dos alunos usuários de Sistema FM.

\section{Referências}

AMERICAN ACADEMY OF AUDIOLOGY. 2011. Clinical practice guidelines: remote microphone hearing assistance technologies for children and youth from birth 21 years. <http://audiologyweb.s3.amazonaws.com/migrated/HAT_Guidelines_Supplement_A.pdf_5399 6ef7758497.54419000.pdf>

BLASCA, W.Q.; Ferrari, D.V. \& Jacob, R.T.S. 2006. Dispositivos eletrônicos aplicados à surdez: conceitos básicos In: Flores K.G.; Lamônica D.A.C. \& Bevilacqua M.C. O processo de comunicação: contribuição para a formação de professores na inclusão de indivíduos com necessidades educativas especiais: 197-213. São José dos Campos: Pulso Editorial.

BLASCA, W.Q. 2012. Telessaúde: intercâmbio técnico científico entre centros de atendimento ao deficiente auditivo [tese]. Bauru (SP): Faculdade de Odontologia de Bauru, Universidade de São Paulo.

BRASIL, 2015. Sistema de frequência devolve qualidade de ensino a pacientes com problemas auditivos. In: Blog da Saúde do Ministério da Saúde 
<http://www.blog.saude.gov.br/index.php/35439-sistema-de-frequencia-devolve-qualidade-deensino-a-pacientes-com-problemas-auditivos>

BRASIL, 2013. Portaria no 1.274, de 25 de junho de 2013. Inclui o Procedimento de Sistema de Frequência Modulada Pessoal (FM) na Tabela de Procedimentos, Medicamentos, Órteses, Próteses e Materiais Especiais (OPM) do Sistema Único de Saúde.

<http://bvsms.saude.gov.br/bvs/saudelegis/gm/2013/prt1274_25_06_2013.html>

CAIRO, A. 2008. Infografía 2.0: visualización interactiva de información en prensa. Madrid: Alamut.

Deficiência, viver sem limite: plano nacional dos direitos da pessoa com / Secretaria de Direitos Humanos da Presidência da República (SDH/PR) / Secretaria Nacional de Promoção dos Direitos da Pessoa com Deficiência (SNPD). Viver sem Limite - Plano Nacional dos Direitos da Pessoa com Deficiência: SDH-PR/SNPD; 2013.

<http://www.desenvolvimentosocial.sp.gov.br/a2sitebox/arquivos/documentos/633.pdf $\geq$

DUARTE, D.D. 2016. Ciência da Informação e Web Design: Interseções teóricas em busca de melhores práticas [dissertação]. Rio de Janeiro (RJ): Escola de Comunicação - Universidade Federal do Rio de Janeiro.

FASSINA, U., Cavalcante, A.L.B. \& Andrade, R.C. 2009. Reflexões sobre a complementariedade imagem e texto, e o seu papel na criação da linguagem da infografia. In: Anais do $2^{\circ}$ Encontro Nacional dos Estudos da Imagem; Londrina, Brasil <http://www.uel.br/eventos/eneimagem/anais/caderno_de_resumos_site.pdf>

FERRARI D.V.; Blasca, W.Q.; Bernardez-Braga, G.R.A. \& Wen, C.L. 2010. Telessaúde: acesso à educação e assistência em audiologia. In: Bevilacqua, M.C.et al. Saúde Auditiva no Brasil: políticas, serviços e sistemas. 189-218. São José dos Campos: Pulso Editorial.

FILATRO, A. \& Piconez, S.C.B. 2004. Design instrucional contextualizado: planejamento, elaboração e avaliação de materiais didáticos para educação a distância. <http://www.abed.org.br/congresso2004/por/pdf/049-TC-B2.pdf.>

JACOB, R.T.S. et al. 2012. Sistema de frequência modulada em crianças com deficiência auditiva: avaliação dos resultados. Revista da Sociedade Brasileira de Fonoaudiologia v.17, n.4:417-421.

JACOB, R.T.S. \& Queiroz-Zattoni, M. 2011. Sistemas de Frequência Modulada (FM). In: Bevilacqua, M.C. el al. Tratado de Audiologia. 727-741. São Paulo: Santos.

LOPES, M.T.; Coutinho, S.G. \& Barbosa, N.C.P. 2012. Contribuições de metodologias de design para a prática pedagógica: apresentação de um esquema inicial. Revista Brasileira de Design da Informação. v.9, n.1:10-20.

PASSOS, R. \& Moura, M. 2007. Design da Informação na hipermídia. Infodesign. v.4, n.2:20-28

PAIXÃO, M.P. 2008. Modelo de educação a distância em hanseníase voltado para a rede de detecção de casos e diagnóstico [tese]. São Paulo (SP): Faculdade de Medicina, Universidade de São Paulo.

PENA DE SÁ, R. 2016. Os princípios de design da informação e sua aplicação em projetos de websites de jornais: estudo de caso do website do jornal O Globo. [dissertação] Brasília (DF): Mestrado em Design - Universidade de Brasília.

PESSOA, A.R. \& Maia, G.G. 2012. A infografia como recurso didático na Educação à Distância. Revista Temática. v.VIII, n.5.

PICOLINI, M.M. \& Maximino, L.P. 2014. Programa de educação em síndromes genéticas: avaliação motivacional de um material educacional on line. Revista CEFAC. v.16, n.1:252259.

SMALL, R.V. \& Arnone, M.P. 1999. Motivation mining: prospecting the web. The Book Report. v.18:42-4.

TURCK, C.J. et al. 2014. A Preliminary Study of Health Care Professionals' Preferences for Infographics Versus Conventional Abstracts for Communicating the Results of Clinical Research. Journal of Continuing Education in the Health Professions. v.34, n.S1:S36-S38. 


\section{Sobre o(a/s) autor(a/es)}

Camila Medina, mestre, FOB-USP, Brasil <camila@fob.usp.br>

Tacianne Kriscia Machado, mestre, FOB-USP, Brasil "Tacianne Alves" <tacianne.alves@hotmail.com>

Regina Tangerino de Souza Jacob, professor doutora, FOB-USP, Brasil <reginatangerino@usp.br>

Cassia Leticia Carrara Domiciano, professora doutora, FAAC-UNESP, Brasil <cassiacarrara@gmail.com> 